\title{
Influence of Polyvinyl Alcohol (PVA) on PVA-Poly- $N$-hydroxyethyl-aspartamide (PVA-PHEA) Microcrystalline Solid Dispersion Films
}

\author{
Zahra Al-Sahaf, ${ }^{1}$ Bahijja Raimi-Abraham, ${ }^{2}$ Mariano Licciardi, ${ }^{2}$ and Laura Modica de Mohac ${ }^{1,2,3}$ (D)
}

Received 7 July 2020; accepted 2 September 2020; published online 2 October 2020

\begin{abstract}
This study was conducted to formulate buccal films consisting of polyvinyl alcohol (PVA) and poly- $N$-hydroxyethyl-aspartamide (PHEA), to improve the dissolution of the drug through the oral mucosa. Ibuprofen sodium salt was used as a model drug, and the buccal film was expected to enhance its dissolution rate. Two different concentrations of PVA $(5 \% \mathrm{w} / \mathrm{v}$ and $7.5 \% \mathrm{w} / \mathrm{v})$ were used. Solvent casting was used to prepare films, where a solution consisting of drug and polymer was cast and allowed to dry. Attenuated total reflection Fourier transform infrared spectroscopy (ATR-FTIR), differential scanning calorimetry (DSC), and scanning electron microscopy (SEM) were used to investigate the properties of films. In vitro dissolution studies were also conducted to investigate drug release. SEM studies showed that films containing a higher concentration of PVA had larger particles in microrange. FTIR studies confirmed the presence of the drug in films and indicated that ibuprofen sodium did not react with polymers. DSC studies confirmed the crystalline form of ibuprofen sodium when incorporated within films. In vitro dissolution studies found that the dissolution percentage of ibuprofen sodium alone was increased when incorporated within the film from 59 to $74 \%$. This study led to the development of solid microcrystalline dispersion as a buccal film with a faster dissolution rate than the drug alone overcoming problem of poor solubility.
\end{abstract}

KEY WORDS: buccal film; PVA; PHEA; ibuprofen sodium; crystalline.

\section{INTRODUCTION}

Tablets represent the most common dosage form available in the market, but they present both pharmaceutical and clinical issues (1). Tablet compression is compromised when using a hygroscopic drug with low density $(2,3)$. Moreover, drugs with low solubility, which are $60 \%$ of marketed compounds, would have a low dissolution into the gastrointestinal tract, causing a reduced bioavailability (4). Even if an oral tablet denotes easy administration for most of the patients, it represents a cause of discomfort for patients with swallowing aversion, pediatric and geriatric population, or with altered absorption diseases that do not benefit from conventional oral route (5-7). Some of the factors associated with low compliance are side effects experienced by the patient and the complexity of treatment, such as multiple dosing times every day (8). Therefore, tablets are not always preferred route of administration.

\footnotetext{
${ }^{1}$ King's College London, London, UK.

${ }^{2}$ University of Study of Palermo, Palermo, Italy.

${ }^{3}$ To whom correspondence should be addressed. (e-mail: laura.1.modica_de_mohac@kcl.ac.uk)
}

Oral cavity film administration has recently emerged as a promising alternative to solid dosage forms (9). Drug delivery via the oral cavity can take place by placing film under the tongue or placing the film on inner cheek allowing rapid absorption of the drug and is, therefore, suitable for fastrelease formulations (10). An important factor influencing oral cavity drug delivery is lack of keratinization in cheek mucosa and sublingual regions resulting in high permeability and systemic delivery $(11,12)$. Therefore, patches applied to buccal mucosa have a potential advantage to by-pass firstpass metabolism leading to an increase in the bioavailability $(7,13,14)$. Furthermore, in comparison to oral tablets, films are ultrathin, flexible, and tend to be less obtrusive and therefore more acceptable (15).

Solvent casting is a prominent method used to prepare solid dispersion as an oral film where the cast solution is dried and cut into the desired size (16). This method is widely used to improve the dissolution of poorly water-soluble drugs and, therefore, to enhance their bioavailability in the body (17). Pharmaceutical film improvement in dissolution rate is often due to the use of hydrophilic polymers which cause an increase in solubilization effect of carrier (18). Furthermore, solid dispersions lead to a drug particle size reduction, improving drug wettability (19). In solid dispersion 
formulation, a key element is the morphological structure of compounds that could be either amorphous or crystalline affecting release profile of API from formulation (20). Modica de Mohac et al., in 2020, described as the different morphological structure could influence release profile and, therefore, important in polymer selection while improvement in release profile is sought (21). Mainly, crystalline and amorphous drugs present different enthalpy, entropy, and free energy that affect stability and dissolution rate of final dosage form (22). Amorphous materials show weaker attractive intermolecular forces that are more easily broken compared to crystalline counterparts, resulting in more soluble material and having a faster dissolution rate (20). However, several studies have shown that the formulation of solid microcrystalline dispersions could both improve dissolution rate and dosage form stability $(16,23)$.

The overall aim of this study was to formulate a solid microcrystalline dispersion as a pharmaceutical film to investigate the effect of the combination of polyvinyl alcohol (PVA) and poly- $N$-hydroxyethyl-aspartamide (PHEA) concentration to increase drug dissolution profile by maintaining its crystalline state. PVA was selected as based polymer due to its water solubility and excellent film-forming properties (24). Furthermore, it is odorless and non-toxic. PVA was combined with novel polymer PHEA (25-27) that has many attractive properties, such as water solubility and absence of toxicity (28). Additionally, it is biodegradable and was used previously in drug delivery systems (29). PHEA is also very hydrophilic and has a high degree of mucoadhesion when formulated at $2.5 \% \mathrm{w} / \mathrm{v}$ in combination with PVA at $5 \% \mathrm{w} / \mathrm{v}$ (30). Present work aimed to prove that increasing concentration of PVA in conjunction with new polymer PHEA would allow obtaining a fast-release profile. Ibuprofen sodium was used as model drugs due to its low solubility of $0.0219 \mathrm{mg} / \mathrm{mL}$ (31). The oral film was produced via solvent casting and film physicochemical properties were characterized using attenuated total reflection Fourier transform infrared spectroscopy (ATRFTIR), differential scanning calorimetry (DSC), and scanning electron microscopy (SEM). In vitro dissolution studies mimicking oral cavity were also conducted.

\section{MATERIALS AND METHODS}

\section{Materials}

Ibuprofen sodium salt [ $>98 \%$ ] purchased from SigmaAldrich, PVA [molecular weight $(\mathrm{Mw})=146,000-186,000 \mathrm{~g} / \mathrm{mol}$, $87-89 \%$ hydrolyzed] purchased from Sigma-Aldrich, and PHEA was synthesized in lab previously $(32,33)$. Buffer tablets $\mathrm{pH} 6.8$ and ethanol were purchased from Sigma-Aldrich.

\section{Sample Preparation: Aqueous Solution}

Aqueous solutions of PVA with a concentration of $5 \% \mathrm{w} / \mathrm{v}$ and $7.5 \% \mathrm{w} / \mathrm{v}$ were prepared by stirring PVA in distilled water using a magnetic stirrer. Distilled water was heated at a temperature of $90^{\circ} \mathrm{C}$, and PVA granules were added and stirred for $2 \mathrm{~h}$ at $80^{\circ} \mathrm{C}$. PHEA at a concentration of $2.5 \% \mathrm{w} / \mathrm{v}$ was added to already made PVA solutions and stirred for $12 \mathrm{~h}$ using a magnetic stirrer. Ibuprofen sodium at a level of $10 \% \mathrm{w} / \mathrm{v}$ was then added to PVA and PHEA solution and stirred for $2 \mathrm{~h}$.

\section{Sample Preparation of Pharmaceutical Films}

The pharmaceutical films were prepared by casting $5 \mathrm{~mL}$ of the solution, described in "Sample Preparation: Aqueous Solution," in a $60-\mathrm{mm}$ plastic petri dish and placing petri dishes in a fume cupboard for $48 \mathrm{~h}$ to allow the solvent to evaporate. After $48 \mathrm{~h}$, the film was dried and was subsequently peeled off gently from petri dish using forceps. Films were then cut into $1 \mathrm{~cm} \times 1 \mathrm{~cm}$ square pieces. Films were produced according to the ratio reported in Table I.

\section{Scanning Electron Microscopy}

SEM studies were conducted on F5 and F6 films to analyze the morphology of particles and to calculate particle size. Images were collected on $1 \mathrm{~cm} \times 1 \mathrm{~cm}$ film section using a Hitachi S5000 Field Emission Gun SEM with a tungsten tip. Before analysis, film samples were coated with $10 \mathrm{~nm}$ of gold. All images were taken using the secondary electron detector. ImageJ software was used to calculate the average particle size of drug particles by taking 100 measurements. Particle distribution index (PDI) was calculated accordingly with the following formula: (PDI) $\left.=<d^{2}>/<d\right\rangle^{2}$ (34).

\section{Attenuated Total Reflection Fourier Transform Infrared Spectroscopy}

FTIR analysis was conducted using a Perkin Elmer Frontier FTIR spectrometer to identify any interactions occurring between molecules, such as hydrogen bonding. Diamond ATR crystal was wiped clean with ethanol, and a background scan was carried out. The sample was then placed onto the crystal. The pressure was applied at a force gauge of 70. A total of 16 scans were taken at a resolution of $2 \mathrm{~cm}^{-1}$ and using a wavelength range of $4000-600 \mathrm{~cm}^{-1}$. Two replicates were carried out for each sample.

\section{Differential Scanning Calorimetry}

DSC analysis was conducted using a DSC 2920 machine (TA instruments) to obtain melting temperature and determine whether materials are present in an amorphous or crystalline form. DSC analysis was conducted at a rate of $5^{\circ} \mathrm{C} / \mathrm{min}$, and samples were heated to $250^{\circ} \mathrm{C}$. Nitrogen purge gas used had a flow rate of $130 \mathrm{~mL} / \mathrm{min}$. Samples were also held isothermally for $5 \mathrm{~min}$. The sample was weighed and placed inside aluminum pans, and the lid was crimped to

Table I. Concentration of PVA, PHEA, and Ibuprofen Sodium Used to Prepare Pharmaceutical Films

\begin{tabular}{llll}
\hline Film & PVA $(\% \mathrm{w} / \mathrm{v})$ & PHEA $(\% \mathrm{w} / \mathrm{v})$ & Ibuprofen sodium $(\% \mathrm{w} / \mathrm{v})$ \\
\hline F1 & 5.0 & - & - \\
F2 & 7.5 & - & - \\
F3 & 5.0 & 2.5 & - \\
F4 & 7.5 & 2.5 & - \\
F5 & 5.0 & 2.5 & 10.0 \\
F6 & 7.5 & 2.5 & 10.0 \\
\hline
\end{tabular}

PVA polyvinyl alcohol, $P H E A$ poly-N-hydroxyethyl-aspartamide 
ensure it was securely closed. Pan was set in DSC instrument with an empty pan as a reference. Two replicates were carried out for each sample.

\section{Drug Content Studies}

UV analysis was used to produce a calibration curve of known concentrations of ibuprofen sodium. Absorbance values were measured using a Perkin Elmer Lambda 35 UV/VIS spectrometer. $0.05 \mathrm{~g}$ of ibuprofen sodium was weighed and dissolved in $100 \mathrm{~mL}$ of ethanol to form a stock solution, then diluted. A small volume of each solution was placed in a 4-mL quartz cuvette to measure absorbance values at a wavelength of $263 \mathrm{~nm}$ and obtain a calibration curve. Drug content was determined in $1 \mathrm{~cm} \times 1 \mathrm{~cm}$ film samples that were weighed and dissolved in $10 \mathrm{~mL}$ of ethanol. Film samples with a weight of approximately $0.03 \mathrm{~g}$ were used. Samples were left in ethanol for 3 days, and the solution was then filtered through a $0.45-\mu \mathrm{m}$ filter. Samples were then analyzed spectrophotometrically at $263 \mathrm{~nm}$ to determine drug content.

\section{In Vitro Dissolution Studies}

Drug release from the film was investigated through dissolution studies; those were conducted using $100 \mathrm{~mL}$ of buffer $\mathrm{pH} 6.8$ solution as a dissolution media. A paddle apparatus was used for this study, and dissolution media was heated to $37^{\circ} \mathrm{C}$ using a magnetic stirrer and stirred at $100 \mathrm{rpm}$. A $1 \mathrm{~cm} \times 1 \mathrm{~cm}$ film section was weighed and placed in dissolution media. Film samples with a weight of approximately $0.03 \mathrm{~g}$ were used. At set time intervals, $10 \mathrm{~mL}$ was drawn out and replaced with $10 \mathrm{~mL}$ of same dissolution media at the same temperature. Time intervals used were $0,2,5,10$, $15,20,25,30,35,40,45,60,120$, and $180 \mathrm{~min}$. Solutions were then analyzed spectrophotometrically at $263 \mathrm{~nm}$. Three replicates were carried out for dissolution of F5 and F6 films, and an average was calculated. Same dissolution method was used to carry out dissolution studies for ibuprofen sodium alone. Weight of ibuprofen sodium used was approximately 0.002 g. Statistical analysis was performed using two-way ANOVA to calculate the $p$ value.

\section{RESULTS}

\section{Physicochemical Characterization}

At first, physical-chemical properties of raw material were characterized to investigate changing in drug solid state after formulation. ATR-FTIR was used to assess main peaks related to PVA, PHEA, and ibuprofen sodium, respectively. Notably, this method allows identification of creation of hydrogen bonding that might indicate the formation of new bonds between drug and polymers (35). Figure 1 presents ATR-FTIR spectra for raw material and peak assignation was reported in Table II. Peak assignation was coherent with literature, and ibuprofen sodium spectra resulted in being consistent with pure drug spectra in the crystalline form (36-38).

Drug solid-state morphology is an essential parameter to evaluate to understand the dissolution profile. DSC analyzed thermal properties of drug and polymers, and thermograph of PVA showed an endothermic peak at $192^{\circ} \mathrm{C}$ recognized to be the melting point of polymer which is present in crystalline form. This finding relates to the literature (39), while PHEA was amorphous and no peak is visible at DSC. Ibuprofen sodium showed a sharp peak at $101^{\circ} \mathrm{C}(\Delta \mathrm{cp} 10.89 \mathrm{~J} / \mathrm{g})$, confirmed by existing literature, which indicates that it is present in its crystalline form (31).

Once patches were formulated, they were evaluated for the presence of a hydrogen bond between polymers and drug to assess the formation of interactions that might occur during the formulation process. Spectra are shown in Fig. 2. ATR-FTIR spectra of pure PVA and films containing only PVA and water (F1 and F2) were consistent with pure PVA spectra, and no water was detected. In formulations F3 and F4, there were observed peaks at $3284 \mathrm{~cm}^{-1}$ for $\mathrm{F} 3$ and $2939 \mathrm{~cm}^{-1}$ for $\mathrm{F} 4$, respectively assigned to O$\mathrm{H}$ group and $\mathrm{C}-\mathrm{H}$ group in PVA. It was also noticed that the presence of peaks at $1633 \mathrm{~cm}^{-1}$ and $1056 \mathrm{~cm}^{-1}$ both related to PHEA chemical structure. But no new peak was observed demonstrating no hydrogen bond formation. In ATR-FTIR spectra of F5 and F6, there were characteristic peaks of ibuprofen sodium which were seen. For instance, a peak was observed at $2950 \mathrm{~cm}^{-1}$ in F5 film due to the asymmetric stretching of the $\mathrm{CH} 3$ group. Also, a peak was observed at $1647 \mathrm{~cm}^{-1}$, which was assigned to stretching of $\mathrm{C}=\mathrm{O}$ group. Fingerprint region of $\mathrm{F} 5$ and $\mathrm{F} 6$ films showed similar activity to raw ibuprofen sodium with peaks at $1252 \mathrm{~cm}^{-1}$ for F6 film which is apportioned to $\mathrm{C}-\mathrm{O}$ stretching. Also, a peak was highlighted at $749 \mathrm{~cm}^{-1}$ of F5 film which is assigned to vibration of $\mathrm{CH}_{2}$ group. No peaks referring to the formation of new bonding were identified.

Therefore, drug morphology within formulations was investigated as it is a well-known effect on solid state on dissolution profile (40). DSC thermographs for F1, F2, F3, and F4 film showed endothermic peaks at $191^{\circ} \mathrm{C}, 189^{\circ} \mathrm{C}$, $191^{\circ} \mathrm{C}$, and $189^{\circ} \mathrm{C}$, respectively. These peaks correspond to the melting temperature of PVA, confirming the crystalline form of PVA in films. Figure 3 shows the thermographs of formulations F5 and F6. Mainly, F5 film showed an endothermic peak at $96^{\circ} \mathrm{C}(\Delta \mathrm{cp} 0.73 \mathrm{~J} / \mathrm{g})$, and $\mathrm{F} 6$ film showed an endothermic peak at $95^{\circ} \mathrm{C}(0.68 \mathrm{~J} / \mathrm{g})$. These two peaks correspond to the melting point of ibuprofen sodium and highlight the crystalline form. PVA crystalline peak, which is reported in Fig. 3, was not identified in F5 and F6, suggesting PVA amorphization. Confirmation about drug crystallinity could be sought to be identified, in the previous paragraph, of the main peak of ibuprofen sodium as a crystalline molecule. Moreover, it was observed that heat capacity ( $\Delta \mathrm{cp}$ ) of each formulation, F5 and F6, is respectively $7.5 \%$ and $6.98 \%$ of $\Delta \mathrm{cp}$ of ibuprofen alone, and this value is coherent with drug loading found for both formulations and described below.

Later, the effect of different concentrations of PVA on particle size was investigated. SEM images indicate that formulation containing $7.5 \%(\mathrm{w} / \mathrm{v})$ of PVA presents particle diameter of $30.05 \pm 3.43 \mu \mathrm{m}$, a 1.38 -fold increase $(p<0.0001)$ with respect to particles obtained with $5.0 \% \%(w / v)$ of PVA with an average diameter of $21.68 \pm 4.09 \mu \mathrm{m}$. Even if PVA usually reduces drug particle size when used as a single polymer, it is well known that it causes drug particle growth when combined with other polymers $(41,42)$. In this study, PVA and PHEA combination lead to obtaining an overall particle diameter that was smaller than $200 \mu \mathrm{m}$, reported to be typical of PVA formulation (43). Particularly, increased particle size could be due to salting out of sodium increasing interaction between ibuprofen molecules. This event is recognized as happening when two soluble polymers are dissolved at higher concentration (44). Figure 4 shows SEM 


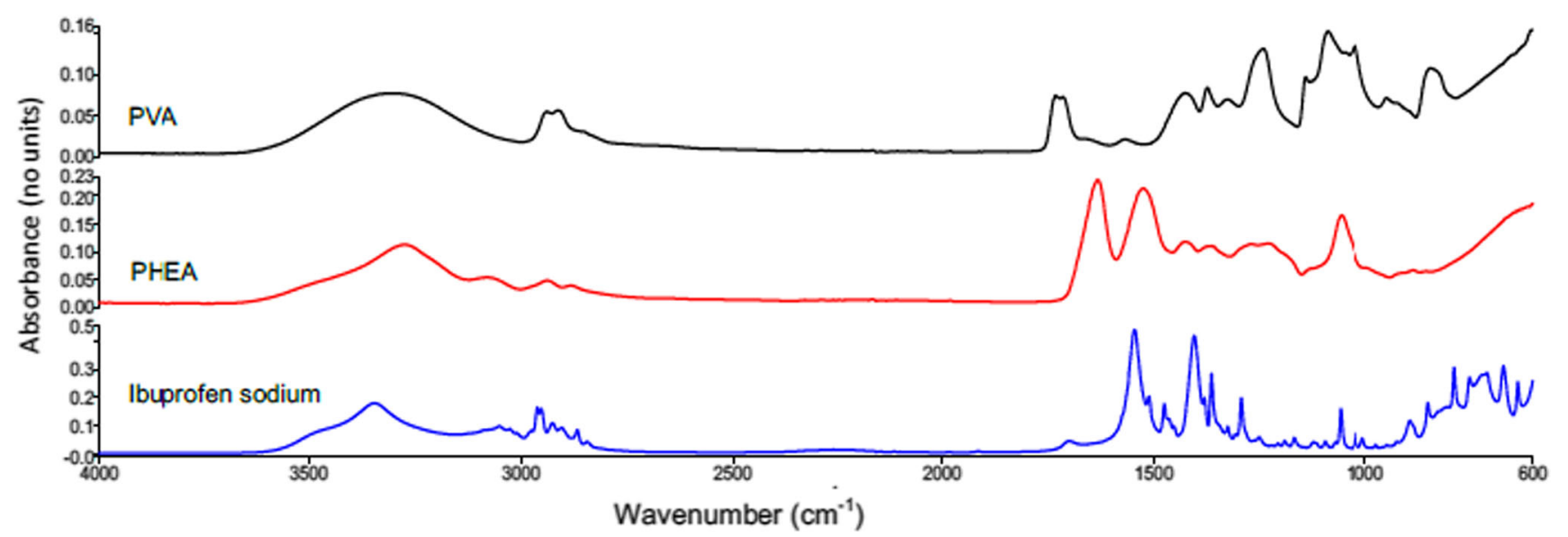

Fig. 1. ATR-FTIR spectra of raw materials PVA, PHEA, and ibuprofen sodium

images of F5 and F6 of samples with two different magnifications. For each formulation, PDI was calculated and found to be respectively 1.08 and 1.12 . This result shows that the drug was not monodispersed due to formation of aggregate that is noticeable in Fig. 4 (45).

\section{Drug Loading Evaluation and Dissolution Study}

Ibuprofen sodium drug loading was evaluated for each formulation. Results showed that ibuprofen sodium loading in film F5 was $6.82 \% \mathrm{w} / \mathrm{v} \pm 0.01$ and $7.01 \% \mathrm{w} / \mathrm{v} \pm 0.01$ in film F6. Drug loading was expected to be $10 \% \mathrm{w} / \mathrm{v}$, and F5 and F6 saw 69\% drug loading efficacy. The lower than anticipated drug content is expected when no stabilizing agents are added to a formulation (46). The in vitro dissolution profile of ibuprofen sodium was analyzed in PBS pH 6.8 to mimic buccal conditions and compared with the release profile of the drug from the film formulation. The dissolution rate percentage was calculated according to assessed

Table II. Peak Assignation for Each Raw Material PVA, PHEA, and Ibuprofen Sodium. Data Are Coherent with Literature Findings (36-

38)

\begin{tabular}{|c|c|c|}
\hline Raw material & Peaks & Assignation \\
\hline PVA & $\begin{array}{l}3290 \mathrm{~cm}^{-1} \\
2939 \mathrm{~cm}^{-1} \\
1732 \mathrm{~cm}^{-1} \\
1567 \mathrm{~cm}^{-1} \\
1421 \mathrm{~cm}^{-1}\end{array}$ & $\begin{array}{l}\text { Stretching } \mathrm{O}-\mathrm{H} \text { group } \\
\text { Asymmetric stretching } \mathrm{C}-\mathrm{H} \text { group } \\
\text { Stretching } \mathrm{C}=\mathrm{O} \\
\text { Stretching } \mathrm{C}=\mathrm{C} \\
\text { Symmetric bending } \mathrm{CH}_{2} \text { group }\end{array}$ \\
\hline PHEA & $\begin{array}{l}3276 \mathrm{~cm}^{-1} \\
2938 \mathrm{~cm}^{-1} \\
1633 \mathrm{~cm}^{-1} \\
1525 \mathrm{~cm}^{-1} \\
1427 \mathrm{~cm}^{-1} \\
1362 \mathrm{~cm}^{-1} \\
1056 \mathrm{~cm}^{-1}\end{array}$ & $\begin{array}{l}\text { Stretching } \mathrm{O}-\mathrm{H} \text { bond } \\
\text { Aliphatic stretching } \mathrm{C}-\mathrm{H} \text { group } \\
\text { Stretching } \mathrm{C}=\mathrm{O} \text { group } \\
\text { Vibrations } \mathrm{N}-\mathrm{H} \text { group } \\
\text { Aliphatic bending } \mathrm{C}-\mathrm{H} \text { group } \\
\text { Bending O-H group } \\
\text { Ester group }\end{array}$ \\
\hline Ibuprofen sodium & $\begin{array}{l}2951 \mathrm{~cm}^{-1} \\
1698 \mathrm{~cm}^{-1} \\
1545 \mathrm{~cm}^{-1} \\
1251 \mathrm{~cm}^{-1} \\
748 \mathrm{~cm}^{-1}\end{array}$ & $\begin{array}{l}\text { Asymmetric stretching } \mathrm{CH}_{3} \text { group } \\
\text { Stretching } \mathrm{C}=\mathrm{O} \text { group } \\
\text { Stretching vibrations } \mathrm{C}=\mathrm{C} \\
\mathrm{C}-\mathrm{O} \text { stretching } \\
\text { Vibration } \mathrm{CH}_{2} \text { group }\end{array}$ \\
\hline
\end{tabular}

PVA polyvinyl alcohol, PHEA poly-N-hydroxyethyl-aspartamide drug loading and related to film weight. Data showed a slower dissolution rate with ibuprofen sodium alone compared to dissolution rate when incorporated within the film. In each profile, it was observed that drug in its crystalline state achieved a condition of supersaturation due to the solubilizing effect of polymer combination $(47,48)$. The dissolution profile of ibuprofen sodium showed a drug release of $59 \%$ at $15 \mathrm{~min}$, while F5 had a drug release of $74 \%$, a 1.25 -fold increase $(p=0.002)$, and F6 of $72 \%$, a 1.22 -fold increase $(p<0.0001)$, resulting in an immediate-like release. This data indicates that the dissolution rate was faster when the drug was incorporated into films compared to medication alone. The calculation of data also confirmed area under curve (AUC) which was increment from $7093 \pm 179 \mu \mathrm{g} / \mathrm{h} / \mathrm{mL}$ for ibuprofen sodium to $7922 \pm 443.8 \mu \mathrm{g} / \mathrm{h} / \mathrm{mL}$ (F5) and $8296 \pm$ $185.1 \mu \mathrm{g} / \mathrm{h} / \mathrm{mL}$ (F6). Moreover, data showed that lower concentration of PVA increases release profile as confirmed from previous literature findings (44). As the difference between two PVA concentrations is 1.02-fold difference, it is considered the possibility that an increase in drug dissolution profile is due to the addition of PHEA itself.

\section{DISCUSSION}

The main aim of this study was to formulate a pharmaceutical film consisting of PVA and PHEA, using ibuprofen sodium as a model drug where an improvement of drug dissolution profile was expected. Furthermore, the effect of varying concentrations of PVA on film properties was examined. At first, physical-chemical characteristics of film were analyzed. Through SEM results, some differences in particle sizes of F5 and F6 films were highlighted. F5 film, which contained a lower concentration of PVA, had smaller particles compared to F6 film, which had a higher concentration of PVA and larger particles. Budhian et al. also found that increasing polymer concentration caused an increase in particle size (49), which further supports the findings of this study. According to literature, PVA should show a smooth, dense surface (50), while ibuprofen sodium should appear as smooth-surfaced rectangular crystalline structures (51). In SEM images obtained, it can be observed that particles had quite an irregular shape due to aggregation, which could also lead to differences in particle size.

When formulating a drug to propose a novel drug delivery system, it is essential to investigate the presence of a bond between drug and polymer. ATR-FTIR spectra F5 


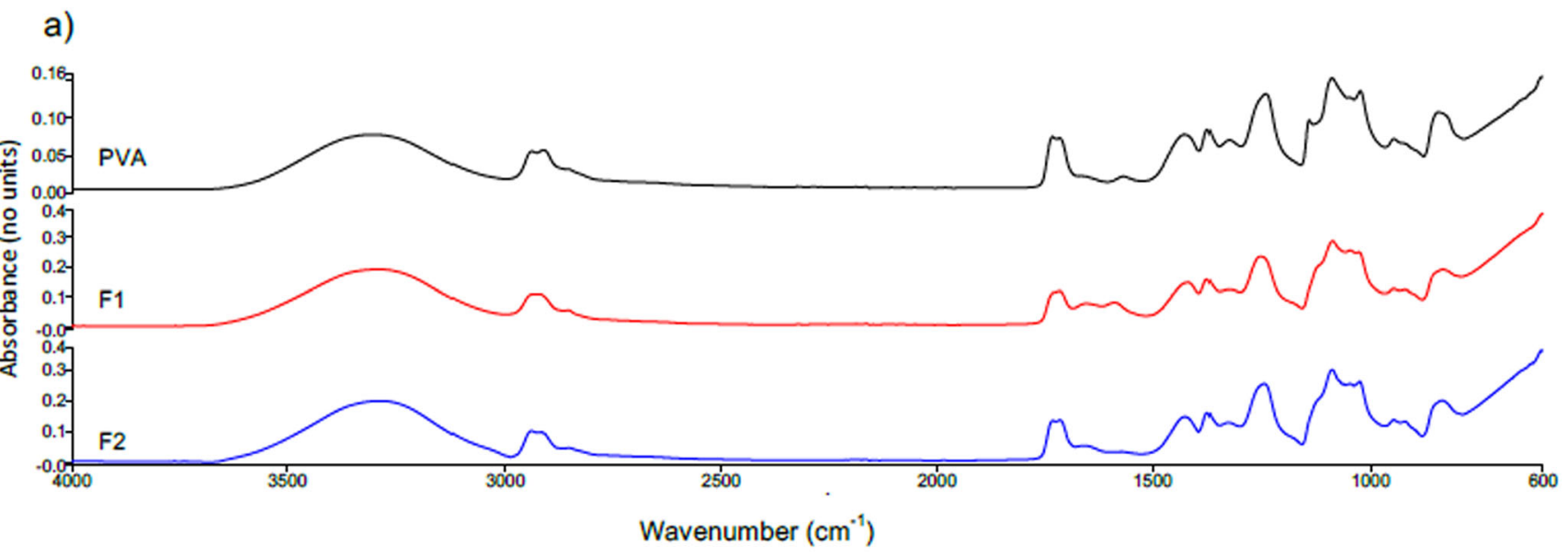

b)

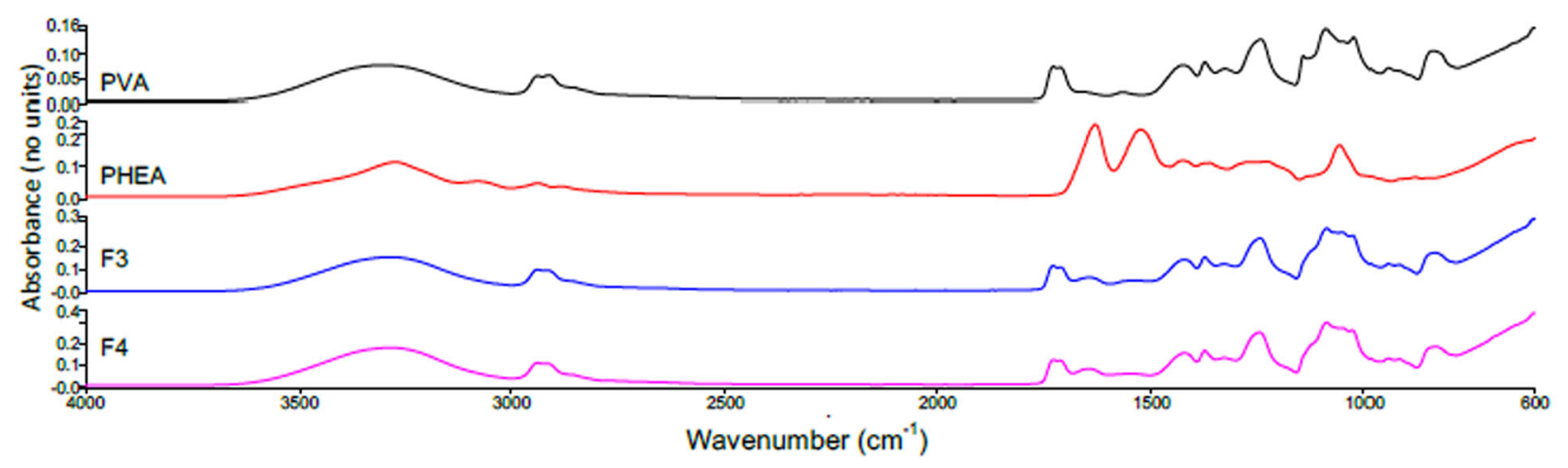

c)

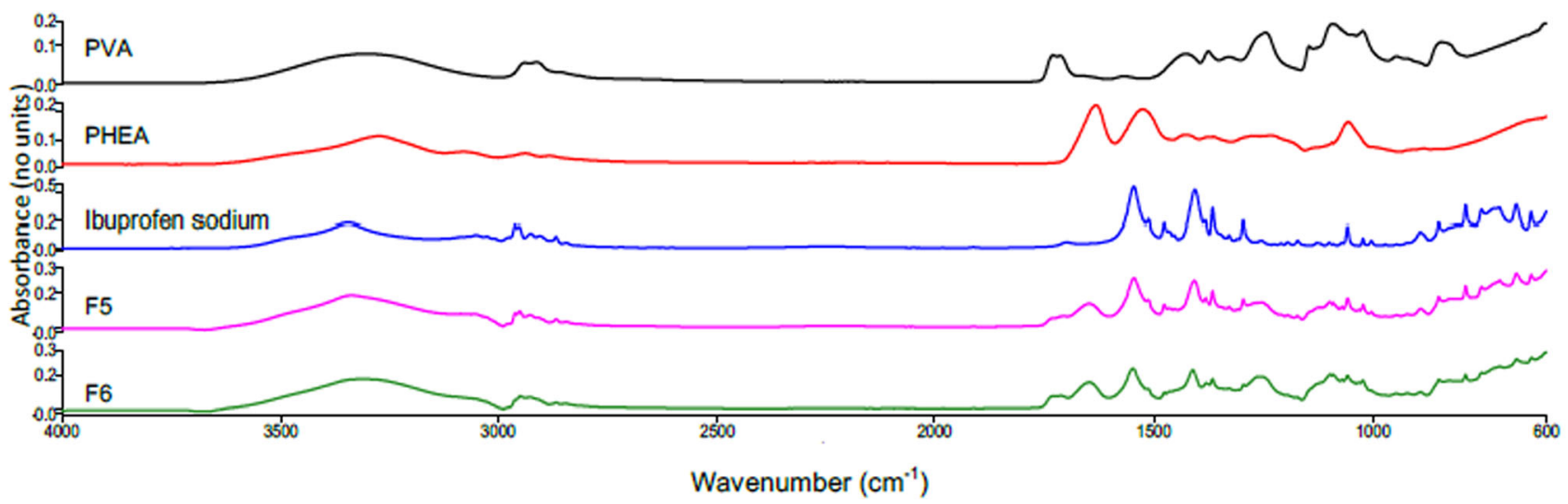

Fig. 2. FTIR spectra of a PVA with F1 and F2; b PVA and PHEA with F3 and F4; and c PVA, PHEA, and ibuprofen sodium with F5 and F6

and F6 with pure ibuprofen sodium showed main peaks of drug and no significant shifts of peaks which confirms that drug was incorporated within films. Drug morphology and particle size used to affect drug dissolution profile once formulated (22,52). DSC results obtained (Fig. 3) highlighted that PVA and ibuprofen sodium were maintained in crystalline forms. DSC thermographs of ibuprofen sodium showed a sharp endothermic peak at $101^{\circ} \mathrm{C}$, and this was assigned to the melting of ibuprofen sodium crystals (53). These findings suggest that ibuprofen sodium solid state was unchanged during the formulation process by the presence of polymers showing lack of strong interactions between drug and polymers within the solid dispersion (54). Baek et al. conducted a study using an ibuprofen-loaded solid dispersion and also found that ibuprofen remained in an unaltered crystalline state after being incorporated within polymers (54). Drug remaining in a crystalline state is vital when formulating a solid microcrystalline dispersion due to the crystalline state being a thermodynamically favored state which makes it more stable than the amorphous state (55). The amorphous 


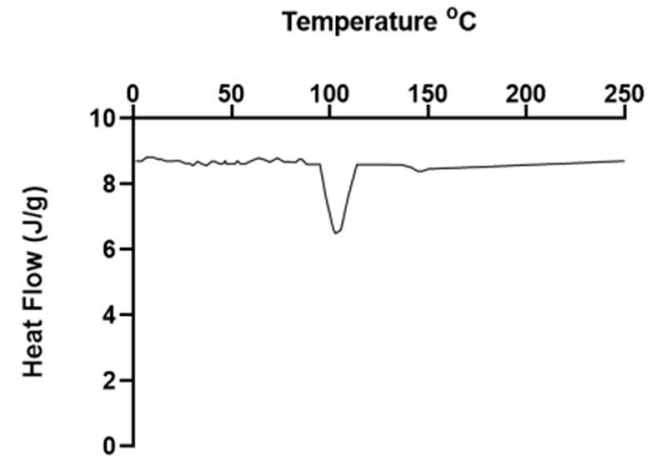

Temperature ${ }^{\circ} \mathrm{C}$

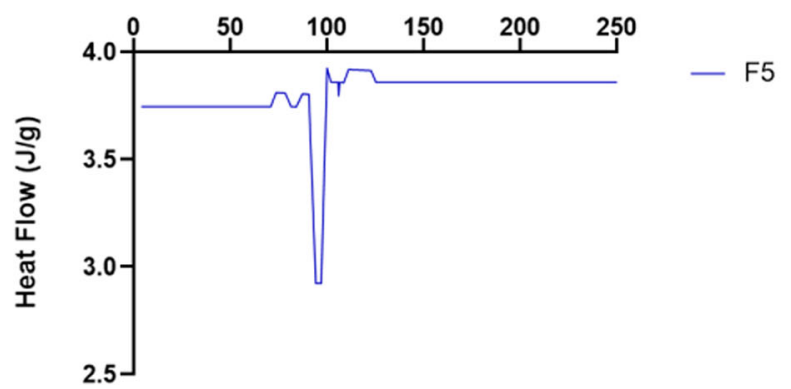

Temperature ${ }^{\circ} \mathrm{C}$

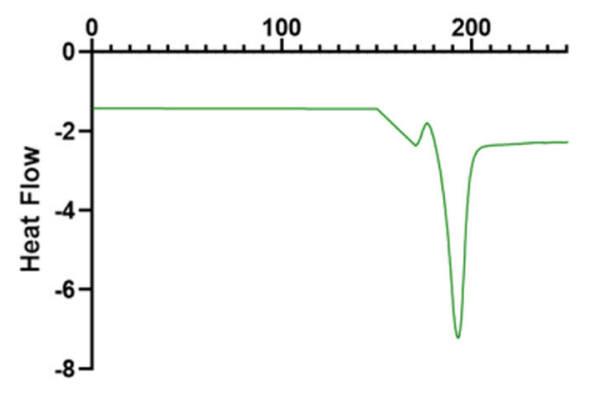

- PVA

\section{Temperature ${ }^{\circ} \mathrm{C}$}

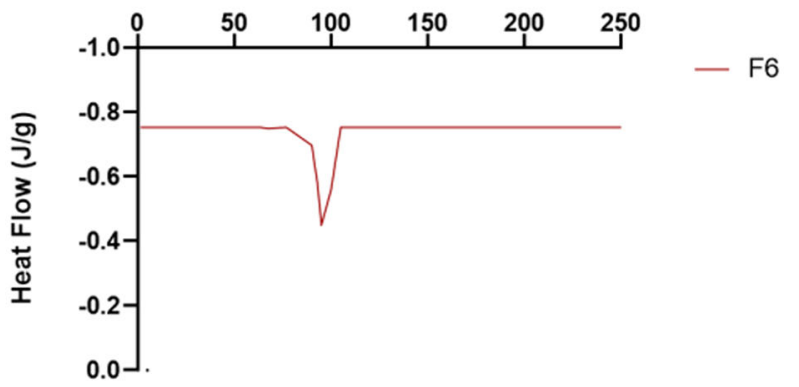

Fig. 3. DSC graphs of ibuprofen sodium and pure PVA compared with $\mathrm{F} 5$ and $\mathrm{F} 6$ that present respectively peaks at $96^{\circ} \mathrm{C}$ and $95^{\circ} \mathrm{C}(\mathrm{endotherm}$ down)

a)

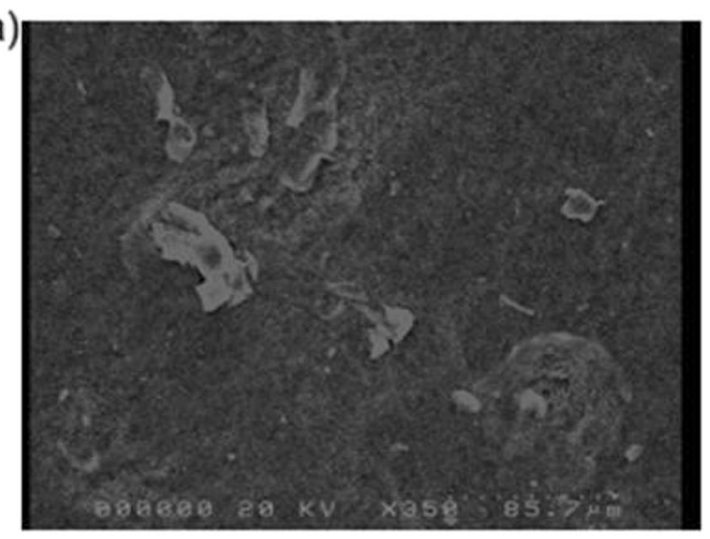

c)

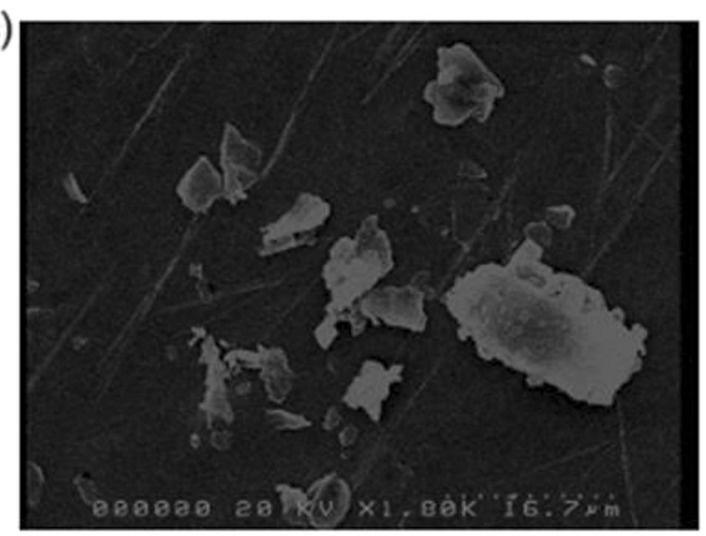

b)

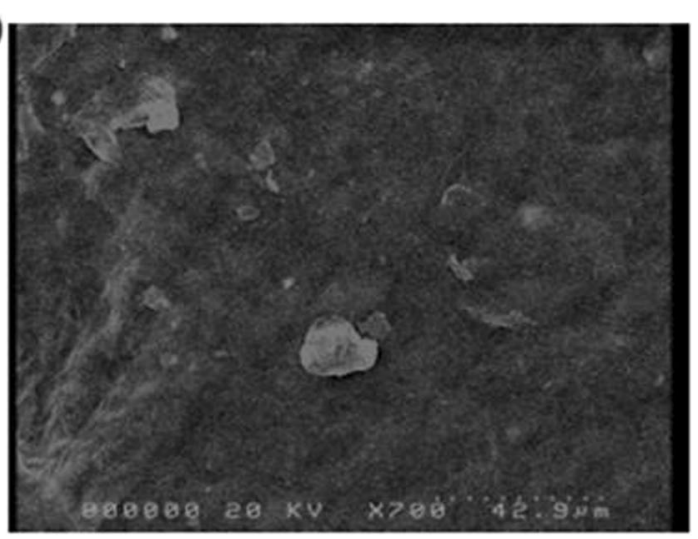

d)

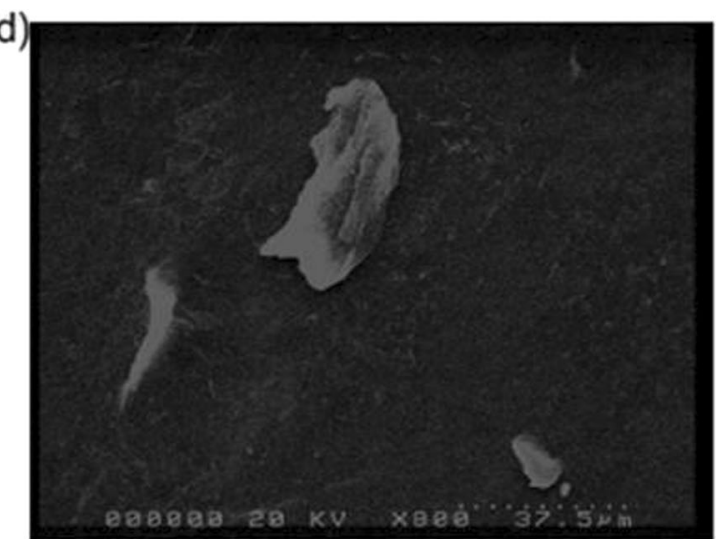

Fig. 4. SEM images of F5 with a magnification of $\mathbf{a} \times 350$ and $\mathbf{b} \times 700$ and F6 with a magnification of $\mathbf{c} \times 1 \mathrm{~K}$ and $\mathbf{d} \times 900$ 

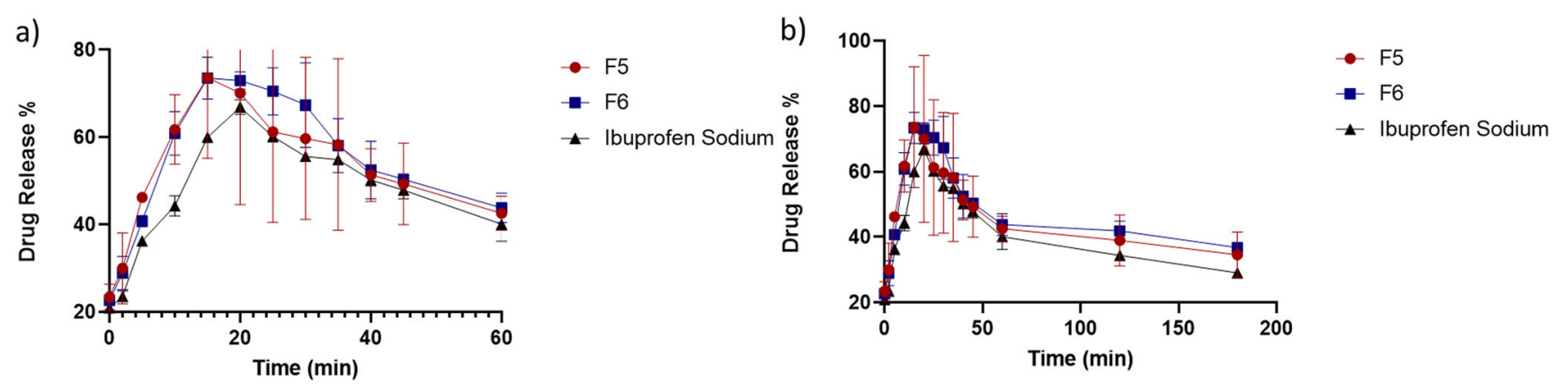

Fig. 5. Dissolution profile of films and ibuprofen sodium a zoomed-in section of the first 60 min of dissolution and $\mathbf{b}$ full dissolution

state has higher internal energy which can lead to higher dissolution rates but lower stability in terms of shelf-life and dissolution study reproducibility (56). However, not all studies have found results which support enhanced dissolution rate of the amorphous state. For instance, Jensen et al. found that crystalline carbamazepine had a faster dissolution rate than the amorphous form of carbamazepine (56). These conflicting results may be due to the unstable nature of amorphous compounds which can lead to recrystallization back into the crystalline state during storage or processing (57). This results in a loss of dissolution and solubility advantage of the amorphous state. Mainly, an amorphous dosage form of ibuprofen sodium was proved to have longterm stability issue and alteration of dissolution profile as determined by Mantas et al. (58).

The results from drug content studies indicate that the F5 film contained $6.82 \%$ of the drug, while F6 film contained $7.01 \%$ of the drug. This result was lower than the content of medicine expected to be in the film (10\%). Small drug content could be due to method of preparation of drug content studies, which could have influenced content uniformity of films in experimental conditions used and is registered when the formulation is not provided with a stabilizer (19). Moreover, evaluation of PDI demonstrated that particles were not monodispersed in the polymer matrix. Woertz et al. conducted content uniformity studies on loperamide films. They found that some of the films had lower drug content than expected which could be attributed to numerous reasons, such as the concentration of polymer and drug used in films (59).

The literature stated that the dissolution rate of poorly soluble drugs improves when the drug is incorporated within polymeric carriers (60). This is due to a solid dispersion forming where the presence of hydrophilic polymers has several effects such as decreasing particle size of drug (61), which means the surface area is more extensive. The diffusion layer of each particle decreases in thickness which leads to a higher dissolution rate (52). Additionally, the dispersion of a drug within polymers is expected to increase drug wettability and also prevent drug aggregation, which will also lead to a faster dissolution rate (61). Increased drug wettability caused by water-soluble polymers is because of each drug crystal that is surrounded by soluble polymeric carriers which can readily dissolve and wet drug particle surface, which increases dissolution rate (62). Results obtained from in vitro dissolution studies (Fig. 5) confirmed this hypothesis as dissolution rate of ibuprofen sodium alone was slower, in comparison to dissolution rate when incorporated within the film. This was highlighted in drug release profile that at $15 \mathrm{~min}$ was $59 \%$. When comparing this to F5 and F6 films, maximum drug release was $74 \%$ and $72 \%$ respectively. Dissolution profiles obtained also show a "spring and parachute," where the pattern has a "spring" which is the initial dissolution of drug and then a "parachute" which refers to prolonged supersaturation of drug (63). Besides, F5 film had a faster dissolution rate due to smaller particles, which will increase surface area for dissolution (61).

\section{CONCLUSION}

This study aimed to formulate solid microcrystalline dispersion as a buccal film consisting of PVA and PHEA and to evaluate the effect of different PVA concentrations of film properties. When comparing two concentrations of PVA used, DSC and ATR-FTIR results showed similar trends, and no interaction between drug and polymers was observed. However, SEM images showed a smaller particle size for F5 film, and drug release profiles showed a faster dissolution rate during the first $15 \mathrm{~min}$. Result confirmed that formulation of solid microcrystalline dispersions was achieved. Mainly, those were able to increase the drug dissolution rate. F5 and F6 films showed the highest drug release at $15 \mathrm{~min}$, respectively $74 \%$ and $72 \%$ for F6 film. Therefore, PVA with a concentration of $5 \% \mathrm{w} / \mathrm{v}$ would be ideal when formulating a pharmaceutical film to achieve a fast-release profile. This study showed the suitability of the solvent casting method to produce fast dissolving film and confirmed the relevance of using different concentrations of PVA to improve dissolution profile. Moreover, addiction of PHEA resulted in being of advantage in increasing dissolution profile and regulating drug particle size.

\section{ACKNOWLEDGMENTS}

The authors would like to acknowledge the University of Palermo for the financial support and for providing the polymer PHEA.

\section{FUNDING}

Open access funding provided by Università degli Studi di Palermo within the CRUI-CARE Agreement.

Open Access This article is licensed under a Creative Commons Attribution 4.0 International License, which permits use, sharing, adaptation, distribution and reproduction in any medium or format, as long as you give appropriate credit to the original author(s) and the source, provide a link to the Creative Commons licence, and indicate if changes were made. The images or other third party material in this article are included in the article's Creative Commons licence, unless indicated otherwise in a credit line to the material. If material 
is not included in the article's Creative Commons licence and your intended use is not permitted by statutory regulation or exceeds the permitted use, you will need to obtain permission directly from the copyright holder. To view a copy of this licence, visit http://creativecommons.org/licenses/by/4.0/.

\section{REFERENCES}

1. Michael E. Aulton pharmaceutics: the design and manufacture of medicines. 2007.

2. Pina MFF, Zhao M, Pinto JFJF, Sousa JJJ, Craig DQM. The influence of drug physical state on dissolution enhancement of solid dispersions prepared via hot-melt extrusion: a case study using olanzapine. J Pharm Sci. 2014;103(4):1214-23. https:// doi.org/10.1002/jps.23894.

3. Larry L, Augsburger SWH. Pharmaceutical dosage forms-tablets: manufacture and process. Control. 2008.

4. Dahan A, Miller JM, Amidon GL. Prediction of solubility and permeability class membership: provisional BCS classification of world's top oral drugs. AAPS J. 2009;11(4):740-6. https:// doi.org/10.1208/s12248-009-9144-x.

5. Jones D. Pharmaceutical applications of polymers for drug delivery; 2004.

6. Gubbins PO, Bertch KE. Drug absorption in gastrointestinal disease and surgery. Pharmacother J Hum Pharmacol Drug Ther. 1989;9(5):285-95. https://doi.org/10.1002/j.18759114.1989.tb04140.x.

7. Boateng J. Drug delivery innovations to address global health challenges for pediatric and geriatric populations (through improvements in patient compliance). J Pharm Sci. 2017;106(11):3188-98. https://doi.org/10.1016/j.xphs.2017.07.009.

8. Li S-C. Factors affecting therapeutic compliance: a review from patient's perspective. Ther Clin Risk Manag. 2008;4:269-86. https://doi.org/10.2147/TCRM.S1458.

9. Nguyen S, Hiorth M. Advanced drug delivery systems for local treatment of oral cavity. Ther Deliv. 2015;6(5):595-608. https:// doi.org/10.4155/tde.15.5.

10. Dodou K. Research and developments in buccal and sublingual drug delivery systems. Pharm J. 2012:288(446).

11. Kraan H, Vrieling H, Czerkinsky C, Jiskoot W, Kersten G, Amorij J. Buccal and sublingual vaccine delivery. J Control Release. 2014;190:580-92. https://doi.org/10.1016/ j.jconrel.2014.05.060.

12. Okamoto H, Nakamori $\mathrm{T}$, Arakawa $\mathrm{Y}$, Iida K, Danjo K. Development of polymer film dosage forms of lidocaine for buccal administration: II. Comparison of preparation methods. J Pharm Sci. 2002;91(11):2424-32. https://doi.org/10.1002/ jps.10228.

13. Sattar M, Sayed OM, Lane ME. Oral transmucosal drug delivery-current status and future prospects. Int J Pharm. 2014;471(1-2):498-506. https://doi.org/10.1016/ j.ijpharm.2014.05.043.

14. Morales JO, McConville JT. Manufacture and characterization of mucoadhesive buccal films. Eur J Pharm Biopharm. 2011;77(2):187-99. https://doi.org/10.1016/j.ejpb.2010.11.023.

15. Lam JKW, Xu Y, Worsley A, Wong ICK. Oral transmucosal drug delivery for pediatric use. Adv Drug Deliv Rev. 2014;73:50-62. https://doi.org/10.1016/j.addr.2013.08.011.

16. Modica de Mohac L, de Fátima PM, Raimi-Abraham BT. Solid microcrystalline dispersion films as a new strategy to improve dissolution rate of poorly water soluble drugs: a case study using olanzapine. Int J Pharm. 2016;508(1-2):42-50. https://doi.org/ 10.1016/j.ijpharm.2016.05.012.

17. Vasconcelos T, Sarmento B, Costa P. Solid dispersions as strategy to improve oral bioavailability of poor water soluble drugs. Drug Discov Today. 2007;12(23-24):1068-75. https:// doi.org/10.1016/j.drudis.2007.09.005.

18. Marano S, Barker SA, Raimi-Abraham BT, Missaghi S, RajabiSiahboomi A, Craig DQM. Development of micro-fibrous solid dispersions of poorly water-soluble drugs in sucrose using temperature-controlled centrifugal spinning. Eur J Pharm Biopharm. 2016;103:84-94. https://doi.org/10.1016/ j.ejpb.2016.03.021.

19. Modica De Mohac L, Caruana R, Pavia FC, Cavallaro G, Giammona G, Licciardi M. Multicomponent solid dispersion as a formulation strategy to improve drug permeation: a case study on anti-colorectal cancer irinotecan. J Drug Deliv Sci Technol. 2019;52:346-54. https://doi.org/10.1016/j.jddst.2019.04.040.

20. Modica de Mohac L, Keating A, de Fátima Pina M, RaimiAbraham B. Engineering of nanofibrous amorphous and crystalline solid dispersions for oral drug delivery. Pharmaceutics. 2018;11(1):7. https://doi.org/10.3390/ pharmaceutics11010007.

21. Modica de Mohac LM, Raimi-Abraham B, Caruana R, Gaetano G, Licciardi M. Multicomponent solid dispersion a new generation of solid dispersion produced by spray-drying. J Drug Deliv Sci Technol. 2020;57(March):101750. https://doi.org/ 10.1016/j.jddst.2020.101750.

22. Baghel S, Cathcart H, O'Reilly NJ, O'Reilly NJ. Investigation into solid-state properties and dissolution profile of spray-dried ternary amorphous solid dispersions: a rational step toward design and development of a multicomponent amorphous system. Mol Pharm. 2018;15(9):3796-812. https://doi.org/ 10.1021/acs.molpharmaceut.8b00306.

23. Démuth B, Farkas A, Balogh A, Bartosiewicz K, Kállai-Szabó $\mathrm{B}$, Bertels $\mathrm{J}$, et al. Lubricant-induced crystallization of itraconazole from tablets made of electrospun amorphous solid dispersion. J Pharm Sci. 2016;105(9):2982-8. https://doi.org/ 10.1016/j.xphs.2016.04.032.

24. Li X, Kanjwal MA, Lin L, Chronakis IS. Electrospun polyvinylalcohol nanofibers as oral fast-dissolving delivery system of caffeine and riboflavin. Colloids Surf B: Biointerfaces. 2013;103:182-8. https://doi.org/10.1016/j.colsurfb.2012.10.016.

25. Di Meo C, Cilurzo F, Licciardi M, et al. Polyaspartamidedoxorubicin conjugate as potential prodrug for anticancer therapy. Pharm Res. 2015;32(5):1557-69. https://doi.org/ 10.1007/s11095-014-1557-2.

26. Paolino D, Licciardi M, Celia C, Giammona G, Fresta M, Cavallaro G. Bisphosphonate-polyaspartamide conjugates as bone targeted drug delivery systems. J Mater Chem B. 2015;3(2):250-9. https://doi.org/10.1039/C4TB00955J.

27. Lo MA, et al. Biocompatibility and biodegradability of electrospun PHEA-PLA scaffolds: our preliminary experience in a murine animal model. Dig J Nanomater Biostructures. 2012;7(2):841-51.

28. Giammona G, Craparo EF. Polymer-based systems for controlled release and targeting of drugs. Polymers (Basel). 2019;11(12):2066. https://doi.org/10.3390/polym11122066.

29. Buscemi S, Palumbo VD, Maffongelli A, Fazzotta S, Palumbo FS, Licciardi M, et al. Electrospun PHEA-PLA/PCL scaffold for vascular regeneration: a preliminary in vivo evaluation. Transplant Proc. 2017;49(4):716-21. https://doi.org/10.1016/ j.transproceed.2017.02.017.

30. Saiano F, Pitarresi G, Cavallaro G, Licciardi M, Giammona G. Evaluation of mucoadhesive properties of $\alpha, \beta$-poly $(\mathrm{N}$ hydroxyethyl)-dl-aspartamide and $\alpha, \beta$-poly(aspartylhydrazide) using ATR-FTIR spectroscopy. Polymer (Guildf). 2002;43(23):6281-6. https://doi.org/10.1016/S00323861(02)00504-9.

31. Lopes DG, Garsuch V, Becker K, Paudel A, Stehr M, Zimmer $\mathrm{A}$, et al. Improving granule strength of roller-compacted ibuprofen sodium for hot-melt coating processing. Int J Pharm. 2016;510(1):285-95. https://doi.org/10.1016/ j.ijpharm.2016.06.049.

32. Licciardi M, Campisi M, Cavallaro G, Cervello M, Azzolina A, Giammona G. Synthesis and characterization of polyaminoacidic polycations for gene delivery. Biomaterials. $2006 ; 27$ (9):2066-75. https://doi.org/10.1016/ j.biomaterials.2005.09.027.

33. Mendichi R, Giacometti Schieroni A, Cavallaro G, Licciardi M, Giammona G. Molecular characterization of $\alpha, \beta$-poly $(\mathrm{N}-2$ hydroxyethyl)-dl-aspartamide derivatives as potential selfassembling copolymers forming polymeric micelles. Polymer 
(Guildf). 2003;44(17):4871-9. https://doi.org/10.1016/S00323861(03)00486-5.

34. Gaumet M, Vargas A, Gurny R, Delie F. Nanoparticles for drug delivery: the need for precision in reporting particle size parameters. Eur J Pharm Biopharm. 2008;69(1):1-9. https:// doi.org/10.1016/j.ejpb.2007.08.001.

35. Craig DQM. The mechanisms of drug release from solid dispersions in water-soluble polymers. Int $\mathrm{J}$ Pharm. 2002;231(2):131-44. https://doi.org/10.1016/S03785173(01)00891-2.

36. Mansur HS, Sadahira CM, Souza AN, Mansur AAP. FTIR spectroscopy characterization of poly (vinyl alcohol) hydrogel with different hydrolysis degree and chemically crosslinked with glutaraldehyde. Mater Sci Eng C. 2008;28(4):539-48. https:// doi.org/10.1016/j.msec.2007.10.088.

37. Park HJ, Ramaraj B, Yoon KR. Graft polymerization of pdioxanone onto polyhydroxyethylaspartamide through ringopening polymerization using organometallic and enzyme catalysts. Des Monomers Polym. 2013;16(5):407-16. https:// doi.org/10.1080/15685551.2012.747158.

38. Grochowicz M, Kierys A. Thermal characterization of polymersilica composites loaded with ibuprofen sodium salt. J Anal Appl Pyrolysis. 2015;114:91-9. https://doi.org/10.1016/ j.jaap.2015.05.004.

39. Gómez I, Otazo EM, Hernández H, Rubio E, Varela J, Ramírez $\mathrm{M}$, et al. Thermal degradation study of PVA derivative with pendant phenylthionecarbamate groups by DSC/TGA and GC/ MS. Polym Degrad Stab. 2015;112:132-6. https://doi.org/10.1016/ j.polymdegradstab.2014.12.027.

40. Talukder R, Reed C, Dürig T, Hussain M. Dissolution and solidstate characterization of poorly water-soluble drugs in presence of a hydrophilic carrier. AAPS PharmSciTech. 2011;12(4):122733. https://doi.org/10.1208/s12249-011-9697-8.

41. Kemala T, Budianto E, Soegiyono B. Preparation and characterization of microspheres based on blend of poly(lactic acid) and poly( $\varepsilon$-caprolactone) with poly(vinyl alcohol) as emulsifier. Arab J Chem. 2012;5(1):103-8. https://doi.org/10.1016/ j.arabjc.2010.08.003.

42. Aina A, Morris A, Gupta M, et al. Dissolution behavior of poly vinyl alcohol in water and its effect on physical morphologies of PLGA scaffolds. UK J Pharm Biosci. 2014;2(1):1. https://doi.org/ 10.20510/ukjpb/2/i1/91124.

43. Jain RA. The manufacturing techniques of various drug loaded biodegradable poly(lactide-co-glycolide) (PLGA) devices. Biomaterials. 2000;21(23):2475-90. https://doi.org/10.1016/S01429612(00)00115-0.

44. Ibrahim H, Bindschaedler C, Doelker E, Buri P, Gurny R. Aqueous nanodispersions prepared by a salting-out process. Int J Pharm. 1992;87(1-3):239-46. https://doi.org/10.1016/03785173(92)90248-Z.

45. Clayton KN, Salameh JW, Wereley ST, Kinzer-Ursem TL. Physical characterization of nanoparticle size and surface modification using particle scattering diffusometry. Biomicrofluidics. 2016;10(5):054107. https://doi.org/10.1063/ 1.4962992.

46. Blanco-Príeto MJ, Fattal E, Gulik A, Dedieu JC, Roques BP, Couvreur P. Characterization and morphological analysis of a cholecystokinin derivative peptide-loaded poly(lactide-coglycolide) microspheres prepared by a water-in-oil-in-water emulsion solvent evaporation method. J Control Release. 1997;43(1):81-7. https://doi.org/10.1016/S0168-3659(96)01474-5.

47. Oki J, Watanabe D, Uekusa T, Sugano K. Mechanism of supersaturation suppression in dissolution process of acidic drug salt. Mol Pharm. 2019;16(4):1669-77. https://doi.org/10.1021/ acs.molpharmaceut.9b00006.

48. Kuentz M. Drug supersaturation during formulation digestion, including real-time analytical approaches. Adv Drug Deliv Rev. 2019;142:50-61. https://doi.org/10.1016/j.addr.2018.11.003.

49. Budhian A, Siegel SJ, Winey KI. Haloperidol-loaded PLGA nanoparticles: systematic study of particle size and drug content.
Int J Pharm. 2007;336(2):367-75. https://doi.org/10.1016/ j.ijpharm.2006.11.061.

50. Ibrahim MM, El-Zawawy WK, Nassar MA. Synthesis and characterization of polyvinyl alcohol/nanospherical cellulose particle films. Carbohydr Polym. 2010;79(3):694-9. https:// doi.org/10.1016/j.carbpol.2009.09.030.

51. Newa M, Bhandari KH, Kim J-A, Yoo BK, Choi HG, Yong CS, et al. Preparation and evaluation of fast dissolving ibuprofenpolyethylene glycol 6000 solid dispersions. Drug Deliv. 2008;15(6):355-64. https://doi.org/10.1080/10717540801952431.

52. Chu KR, Lee E, Jeong SH, Park E-S. Effect of particle size on dissolution behaviors of poorly water-soluble drugs. Arch Pharm Res. 2012;35(7):1187-95. https://doi.org/10.1007/s12272012-0709-3.

53. Lee JW, Thomas LC, Schmidt SJ. Investigation of heating rate dependency associated with loss of crystalline structure in sucrose, glucose, and fructose using a thermal analysis approach (part I). J Agric Food Chem. 2011;59(2):684-701. https://doi.org/ 10.1021/jf1042344.

54. Baek HH, Kim D-H, Kwon SY, Rho SJ, Kim DW, Choi HG, et al. Development of novel ibuprofen-loaded solid dispersion with enhanced bioavailability using cycloamylose. Arch Pharm Res. 2012;35(4):683-9. https://doi.org/10.1007/s12272-012-04124.

55. Murdande SB, Pikal MJ, Shanker RM, Bogner RH. Aqueous solubility of crystalline and amorphous drugs: challenges in measurement. Pharm Dev Technol. 2011;16(3):187-200. https:// doi.org/10.3109/10837451003774377.

56. Yoshioka M, Hancock BC, Zografi G. Crystallization of indomethacin from amorphous state below and above its glass transition temperature. J Pharm Sci. 1994;83(12):1700-5. https:// doi.org/10.1002/jps.2600831211.

57. Konno H, Taylor LS. Influence of different polymers on crystallization tendency of molecularly dispersed amorphous felodipine. J Pharm Sci. 2006;95(12):2692-705. https://doi.org/ 10.1002/jps.20697.

58. Mantas A, Labbe V, Loryan I, Mihranyan A. Amorphisation of free acid ibuprofen and other profens in mixtures with nanocellulose: dry powder formulation strategy for enhanced solubility. Pharmaceutics. 2019;11(2):68. https://doi.org/10.3390/ pharmaceutics 11020068 .

59. Woertz C, Kleinebudde P. Development of orodispersible polymer films with focus on solid state characterization of crystalline loperamide. Eur J Pharm Biopharm. 2015;94:52-63. https://doi.org/10.1016/j.ejpb.2015.04.036.

60. Rodde MS, Divase GT, Devkar TB, Tekade AR. Solubility and bioavailability enhancement of poorly aqueous soluble atorvastatin: in vitro, ex vivo, and in vivo studies. Biomed Res Int. 2014;2014:1-10. https://doi.org/10.1155/2014/463895.

61. El-Badry M, Fetih G, Fathy M. Improvement of solubility and dissolution rate of indomethacin by solid dispersions in Gelucire 50/13 and PEG4000. Saudi Pharm J. 2009;17(3):217-25. https:// doi.org/10.1016/j.jsps.2009.08.006.

62. Van Den Mooter G. Solid dispersions as a formulation strategy for poorly soluble compounds. Annu Symp Finish Soc Phys Pharm. 2009;1(January):1-37.

63. Liu C, Chen Z, Chen Y, Lu J, Li Y, Wang S, et al. Improving oral bioavailability of sorafenib by optimizing "spring" and "parachute" based on molecular interaction mechanisms. Mol Pharm. 2016;13(2):599-608. https://doi.org/10.1021/ acs.molpharmaceut.5b00837.

Publisher's Note Springer Nature remains neutral with regard to jurisdictional claims in published maps and institutional affiliations. 